\title{
A Reality in Emergency Medicine: Subspecialization
}

\author{
Mehmet Ali Aslaner \\ Clinic of Emergency, Nevşehir State Hospital, Nevşehir, Turkey
}

Cite this article as: Aslaner MA. A Reality in Emergency Medicine: Subspecialization. Eurasian J Emerg Med 2017; $16: 144-7$.

\begin{abstract}
Emergency medicine is a rapidly evolving discipline, encompassing almost all other branches of medicine. This broad spectrum encourages physicians to improve themselves in a specific area because emergency departments are no longer the place where just first treatment is administered, but also where treatment is maintained. This paper aims to identify the needs and barriers of the advanced training or subspecialization in emergency medicine in Turkey using other countries as examples.
\end{abstract}

Keywords: Emergency medicine, fellowships, residency

\section{Introduction}

Emergency medicine (EM) was recognized in 1993 in Turkey and has since evolved as a specialty at an increasing rate (1). The duration of training is four years similarly to other countries, and a certificate of completion of training is issued after compulsory service by the Ministry of Health. Accreditation for all specialties and advanced trainings (subspecialties) is approved by the Board of Medical Specialties in Turkey.

Subspecialization, which first emerged in internal medicine and general surgery, originated in the 1960s in Turkey (2). These subspecialties, with time, have become today's specialties (such as plastic and cardiovascular surgery). Also, these branches now have their sub-branches (child subspecialties). Although EM is similar to these main branches in terms of broad scope, there is no future plan regarding advanced training or subspecialization in EM in Turkey (3).

\section{Why do we need subspecialization?}

Firstly, there are various areas closely related to EM such as prehospital EM, disaster medicine, and medical toxicology, but these areas specifically are not affiliated with any discipline. Prehospital EM is provided by general practitioners in Turkey. Disaster situations are coordinated by the Health Disaster Coordination Center, which is an organization of the Ministry of Health and is not an academic institution. Although toxicology is maintained by pharmacologists, it is not enough for clinical practice. There is an ongoing debate regarding critical care and pediatric EM. There are only a few countries (including Turkey) with intensive care units (ICUs) in the emergency departments (EDs) (4). Many academic and non-academic EDs have level one to level three ICUs. Although critical care is provided by emergency physicians (EPs) in these special areas, there is no opportunity for advanced training in this discipline for EPs (5). Also, pediatric EM is a subspecialization only for pediatricians, but EPs treat nearly half of children with medical problems and more than half of the children with trauma presentations in many EDs (6). As a result, sufficient medical education, public health, and patient care quality are not achieved because of all of these shortcomings.

Secondly, emergency residents and attending physicians need to improve in their areas of interest. However, they cannot enhance their 
Table 1. The subspecialties and dual certifications of EM in countries that have advanced trainings

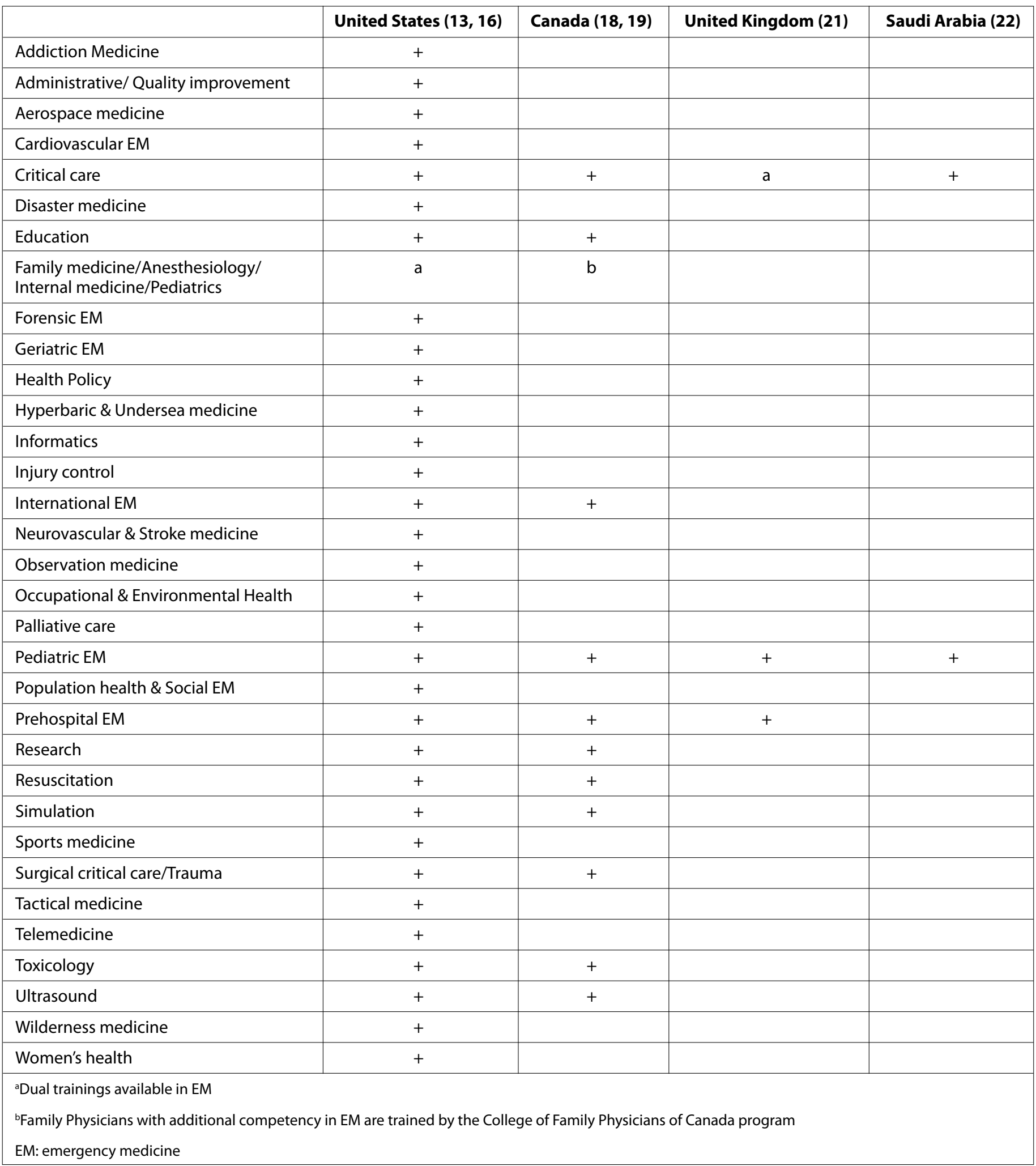

trainings due to the aforementioned limitations and work intensity. This has led to job dissatisfaction. In addition, medical students are reluctant to become an $\mathrm{EP}$, and nearly half of the quota of $\mathrm{EM}$ remains unfilled because EM is not preferred by medical students due to academic and job-related concerns $(7,8)$.
Finally, there are two associations in Turkey, namely Emergency Physicians Association of Turkey and Emergency Medicine Association of Turkey, and both associations have more than 10 different working groups. Each group has various EPs who are interested in the area, and they organize several trainings. These groups and ed- 
ucated EPs are increasing in Turkey, although they are not officially accredited.

\section{What are the barriers and limitations?}

Presently (in 2017), the number of EPs in Turkey includes 953 residents, 1445 attendings, and 250 academic staff, and there are 95 academic EDs (9). In addition, general practitioners work in other EDs. The number of EPs is still not sufficient for standard patient care, and more educated EPs are needed in the public sector. However, the desired number of EPs cannot be trained because one-third of the EM residents resign during the training process due to stress factors and concerns about their futures (10).

There is still a lack of standardization in the medical education of emergency resident training. Some academic EDs have enough trainers or materials, while others do not (11). New academic EDs have been established, but they do not have enough trainers or policies for education and quality health service. Residents' education remains incomplete during the training process; therefore, they apply for postgraduate education and courses individually. If there is advanced training such as subspecialization in EM in future, it should be started at certain academic faculties with enough trainers, opportunities, and international connections.

\section{Global examples}

Many countries have recognized subspecialties in EM at different times and in different areas. Some are very old and others are new. The US is the first example of this evolution. EM, established in 1970s, introduced the first accredited subspecialty as a pediatric EM in 1991. Thereafter, sports medicine and medical toxicology were recognized in 1992 (12). Presently, there are 34 fellowship programs, nine of which are accredited by the American Board of Emergency Medicine (ABEM) in the US (Table 1) $(13,14)$. Most recently, there are available options for the recognition of clinical ultrasonography, either as a subspecialty or a designation of focused practice (15). Dual accreditation is also another option for EPs. One can complete the training in both specialties as EM/anesthesiology, internal medicine, pediatrics, or family medicine (Table 1) (16). All of these advanced trainings take one or two additional years, nevertheless only $4.3 \%$ of ABEM physicians have a subspecialty certificate (17).

Canadian EPs have opportunities to choose various advanced trainings. Pediatric EM and intensive care are accredited fellowship programs by the Royal College of Physicians and Surgeons of Canada. Also, there are unaccredited fellowships and degree programs (Table 1) (18). One or two years of training are usually spent to attain advanced education during or after residency trainings, and these programs exist in many academic EDs (19).

In the UK, there are two subspecialties-pediatric EM was recognized in 2001 by the General Medical Council and prehospital EM was recognized in $2011(12,20)$. Only $65 \%$ of the pediatric EM positions are chosen by EPs in the UK. One additional year of dedicated full-time training is required for both certifications. Also, EPs can acquire a dual certificate of completion of training in both EM and intensive care medicine (Table 1) (21).

In Saudi Arabia, after 4 EPs graduated in 2004, EM has evolved rapidly. There are two accredited fellowship programs by the Saudi Com- mission for Health Specialties-pediatric EM and critical care (Table 1). Both trainings take two additional years to attain a subspecialty (22). Also, there are future plans regarding five other fellowships-medical toxicology, prehospital EM/disaster medicine, undersea and hyperbaric medicine, emergency ultrasound, and sports medicine (23).

\section{Conclusion}

Subspecialization should be of high priority and absolutely considered for the development of EM. Turkey has witnessed wars and earthquakes for many years due to geopolitical positions, and therefore disaster medicine and prehospital EM should be included in advance training in EM. Medical toxicology, pediatric EM, and critical care should also be considered as a subspecialty in EM due to clinical need. Because EM has lower rates in terms of both career choice and the number of working physicians in Turkey, we suggest that the Government should make subspecialization in EM more attractive to the medical students and motivate the residents in order to improve education and health care quality.

Peer-review: Externally peer-reviewed.

Conflict of Interest: No conflict of interest was declared by the authors.

Financial Disclosure: The authors declared that this study has received no financial support.

\section{References}

1. Aksay E, Sahin H, Kiyan S, Ersel M. Current status of emergency residency training programs in Turkey: after 14 years of experience. Eur J Emerg Med 2009; 16: 4-10. [CrossRef]

2. İzgi C, Çoban M. Exchange of Specialty Branches in Medical Science at Republican Era. Lokman Hekim Journal of History of Medicine and Folk Medicine 2014; 4: 26-37.

3. Emergency Medicine Subspecialties. (Accessed 13 May 2017, Available from: http://www.acilci.net/acil-tip-yan-dallari/.)

4. Sahadeo A, McDowald K, Direktor S, Hynes EA, Rogers ME. Effectiveness of collaboration between emergency department and intensive care unit teams on mortality rates of patients presenting with critical illness: a quantitative systematic review protocol. JBI Database System Rev Implement Rep 2017; 15: 66-75. [CrossRef]

5. Aslaner MA, Akkaş M, Eroğlu S, Aksu NM, Özmen MM. Admissions of critically ill patients to the ED intensive care unit. J Emerg Med 2015; 33: 501-5. [CrossRef]

6. Örnek Z, Piskin IE, Karaci M, Yüksek N, Firat CK, Üstündag GH. Assessment of the Suitability of the Emergency Departments at the Hospitals in the Western Black Sea Region for Pediatric Patients. Cocuk Acil ve Yogun Bakım 2016; 3: 15. [CrossRef]

7. Kaynak MF, Altintop I, Cikriklar HI, Ozdemir F, Gafurogulları S, Koca N. The analysis of occupational satisfaction of resident physicians having emergency medicine education. Eur J 2016; 2: 7-11. [CrossRef]

8. Satar S, Cander B, Avci A, Acıkalin A, Orak M, Acin M. Why speciality in Emergency Medicine is not preferred. Eurasian J Emerg Med 2013; 12: 234-6. [CrossRef]

9. Yanturalı S. Today's Academic Emergency Medicine in Turkey with Numbers. Turkiye Klinikleri Journal of Emergency Medicine-Special Topics 2016; 2: 65-8.

10. Sen J, Büyükcam F, Akpinar S, Karakiliç E. The Vacancies and Preferability of Emergency Medicine Training in Recent Years in Turkey. Eurasian J Emerg Med 2013; 12: 180. [CrossRef] 
11. Fowler J. Establishment of the Academic Emergency Department at University of Dokuz Eylül and the Others. Turkiye Klinikleri Journal of Emergency Medicine-Special Topics 2016; 2: 4-11

12. Maitra S, Christian MR, Aks SE. Subspecialisation in emergency medicine: An international perspective. Emerg Med Australas 2016; 28: 465-7. [CrossRef]

13. Shafer K, Stuntz B, Malik D, Badulak J, Emlet L, Mohr N. EMRA Fellowship Guide: Opportunities for Emergency Physicians. 2016.

14. Subspecialties at a Glance - January 2017. (Accessed 13 May 2017, Available from: https://www.abem.org/public/subspecialty-certification.)

15. Recognition of Clinical Ultrasonography. (Accessed 22 May 2017, Available from: https://www.abem.org/public/subspecialty-certification/clinical-ultrasonography.)

16. Combined Training Programs (Accessed 13 May 2017, Available from: https://www.abem.org/public/emergency-medicine-training/combined-training-programs.)
17. Edmonds MJR, Hamilton S, Brichko L. Subspecialisation in emergency medicine: A specialty Available from: the crossroads. Emergency Medicine Australasia 2016;28:462-4. [CrossRef]

18. Resident Fellowship Directory. (Accessed 13 May 2017, Available from: http://caep.ca/CAEPFellowshipDirectory.)

19. Thoma B, Mohindra R, Woods RA. Enhanced training in emergency medicine: the search and application process. CJEM 2015; 17: 565-8. [CrossRef]

20. Sub-specialty Training in Pre-hospital Emergency Medicine. (Accessed 13 May 2017, Available from: http://www.gmc-uk.org/PHEM_Guide.pdf_51046578.pdf.)

21. Curriculum and Assessment Systems For Training in Emergency Medicine 2015. (Accessed 13 May 2017, Available from: http://www.gmc-uk. org/education/emergency_medicine.asp.)

22. Fellowship Programs. (Accessed 13 May 2017, Available from: http://ngha. med.sa/English/Professionals/pgme/Pages/FellowshipPrograms.aspx.)

23. Medical Specialty Selection Guide for Medical Graduates. (Accessed 13 May 2017, Available from: http://www.scfhs.org.sa/en/Media/OtherPublications/Pages/default.aspx.) 